
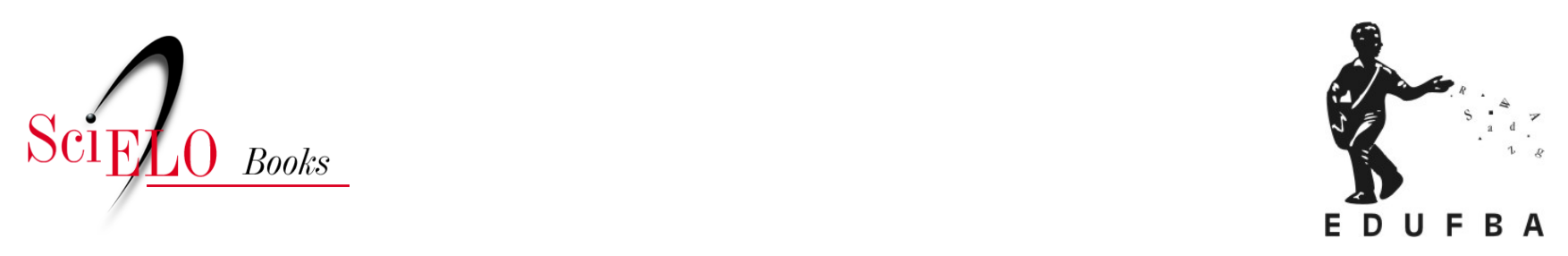

\title{
Condições de possibilidade históricas para a emergência de políticas de saúde bucal no pós-constituinte
}

\author{
Thais Regis Aranha Rossi
}

\section{SciELO Books / SciELO Livros / SciELO Libros}

ROSSI, T.R.A. Condições de possibilidade históricas para a emergência de políticas de saúde bucal no pós-constituinte. In: Produção social das políticas de saúde bucal no Brasil [online]. Salvador: EDUFBA, 2018, pp. 65-91. ISBN 978-85-232-2022-8. https://doi.org/10.7476/9788523220228.0004.

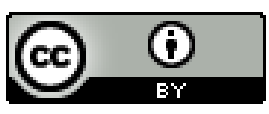

All the contents of this work, except where otherwise noted, is licensed under a Creative Commons Attribution 4.0 International license.

Todo o conteúdo deste trabalho, exceto quando houver ressalva, é publicado sob a licença Creative Commons Atribição 4.0. 


\section{CONDIÇÕES DE POSSIBILIDADE HISTÓRICAS PARA A EMERGÊNCIA DE POLÍTICAS DE SAÚDE BUCAL NO PÓS-CONSTITUINTE}

\section{Papel do Instituto de Pesquisas Econômicas Aplicadas (IPEA) e Finsocial}

Além de ter servido como lócus para elaboração do Praod, o Instituto de Pesquisas Econômicas Aplicadas desempenhou um papel importante no espaço de formulação das políticas de saúde bucal, no início dos anos 1980. Em publicação recente do Instituto, diz-se sobre o seu papel de "refletir sobre os principais problemas nacionais, visando o aperfeiçoamento das políticas públicas em diversos campos”. (IPEA, 2008) O mesmo também foi ressaltado pelos entrevistados Pinto e Vianna, em 2014.

O gerenciamento do financiamento da expansão da fluoretação no país ficou a cargo do Banco Nacional da Habitação (BNH), substituído posteriormente pela Caixa Econômica Federal (CEF). Já as ações de saúde do escolar ficaram localizadas na Fundação de Assistência ao Estudante (FAE) do MEC. (PINTO, 1993) As ações que compunham o Finsocial não passaram por processo de planejamento e a saúde bucal entrou no último momento. Solon Magalhães Vianna e Vitor Gomes Pinto foram responsáveis pela formulação dos programas.

Esse programa nacional que continha diretrizes políticas para a saúde bucal emerge da possibilidade de recursos pelo Finsocial, dentro do Plano de reorientação da assistência odontológica IPEA, que representava um espaço de formulação de políticas. Solón Magalhães Vianna ingressou no Instituto em 1975, após ter exercido a direção do Departamento de Planejamento de Saúde da Secretaria de Saúde de Brasília. Vitor Gomes Pinto também ingressou no mesmo ano, quando estava se formando um núcleo de saúde, com o Eduardo Kertész. As propostas de 
ação que constavam dos documentos oficiais do IPEA, assinados por Vianna e Pinto, envolviam a priorização para a região Nordeste, os sistemas de abastecimento de maior alcance social, reativação dos sistemas desativados até junho de 1983 e participação popular e das companhias de saneamento para que as medidas tivessem continuidade após findada a participação do Finsocial para a fluoretação das águas de abastecimento público. (VIANNA; PINTO, 1983)

Observou-se que o IPEA passou a exercer importância nas ações de saúde bucal no âmbito nacional, justificada pelo espaço aparentemente neutro que exercia frente aos conflitos que existiam entre o MS e o MPAS. Ademais, seus membros ocupavam uma posição dominante, sendo identificados como experts de estado em relação ao campo do poder. Nesse sentido, esses membros, muitas vezes tendo saído do seu campo de origem, não eram identificados conforme suas formações profissionais de início.

\section{Luta pela democratização e a saúde}

Escorel (2008) e Paim (2008) relacionaram o momento histórico de luta pela democratização do país com as lutas setoriais na saúde relacionadas com a reforma do sistema de saúde. Paim (2008) analisa a Reforma Sanitária Brasileira como uma reforma social centrada na democratização da saúde, democratização do Estado e democratização da sociedade; um fenômeno histórico social que pode ser descrito conforme o ciclo ideia-proposta-projeto-movimento-processo.

A ideia se relaciona a sua representação inicial. A criação do Cebes, em 1976, e o lançamento da Saúde em Debate assim como a fundação da Associação Brasileira de Saúde Coletiva (Abrasco), em 1979, foram consideradas pelo autor como expressão da síntese das práticas teórica e política. (PAIM, 2008) A proposta correspondeu ao conjunto articulado de princípios e proposições políticas, sendo que o projeto foi sistematizado no Relatório Final da VIII Conferência Nacional de Saúde (CNS). O movimento de democratização da saúde emerge com o Cebes e perpassa distintas conjunturas. Já a Reforma Sanitária Brasileira (RSB) enquanto processo foi desencadeada após a VIII CNS com a implantação do Sistema Unificado e Descentralizado de Saúde (SUDS), a instalação da Comissão Nacional de Reforma Sanitária e a própria promulgação da Constituição Federal, em 1988. (PAIM, 2008)

No bojo do movimento da RSB, na luta pela democratização, surgem movimentos dos dentistas com pautas pela democratização do país e pautas específicas para formalização de respostas do Estado frente aos problemas bucais que serão tratados a seguir. O momento de elaboração da Constituição Federal, a partir de 1985, promulgada em 1988, é caracterizado como um grande período de lutas. 


\section{Encontros Nacionais de Administradores e Técnicos de Serviços Públicos (Enatespo)}

Em dezembro de 1984, foi realizado o I Encontro Nacional de Administradores e Técnicos de Serviços Públicos Odontológicos (Enatespo) com o tema "proposta de política nacional para um governo democrático”, em Goiás. Serra (1998) caracterizou o Enatespo como um movimento contra-hegemônico nos anos 1980. O Enatespo ocorreu em um cenário de crescimento dos movimentos de redemocratização do país, o que estimulou a reconquista dos espaços políticos para discutir o país e posições políticas acerca dos problemas nacionais, e, assim, reuniu representantes da Odontologia que exerciam cargos no campo burocrático, instituições de ensino, entidades de classe e serviços odontológicos.

[...] até em 82 os Governadores não eram eleitos por voto popular. Eles eram eleitos indiretamente pela assembleia legislativa. Em 82, houve eleições diretas para governadores, então em vários estados foram eleitos governadores de oposição à ditadura militar. Portanto, a partir de 83, novos secretários estaduais de saúde, novos coordenadores, pessoas incumbidas da saúde bucal assumiram essas funções onde a oposição ganhou. Essas pessoas trataram de se articular a nível nacional. Nós inventamos o Enatespo, nós criamos um encontro nacional que chamamos de Encontro Nacional de administradores e técnicos do serviço público odontológico, a sigla é Enatespo. [...] vem com influência do Movimento Brasileiro de Renovação Odontológico, tem todo um processo que vai desembocar no Enatespo [...]. (Entrevistado 10, dentista, professor universitário)

A própria denominação do Enatespo expressa o lócus inicial de motivação do evento no campo burocrático enquanto administradores e técnicos do serviço odontológico, conforme apontou um dos entrevistados. O relatório final expressava sugestões para a elaboração de proposta de uma política de saúde pública em Odontologia no nível nacional:

- incentivo à indústria nacional de medicamentos para produção de material odontológico;

- padronização, no nível nacional, de ações preventivas e curativas, priorizando faixas etárias que são epidemiologicamente mais vulneráveis à cárie dental com técnicas e equipamentos simplificados para ampliar a cobertura, com menor custo, mas sem comprometer a qualidade, assim como desenvolver campanhas educativas a nível nacional;

- definição de níveis de complexidade e responsabilidade crescentes e convênio com universidades para encaminhamento de casos especializados; 
- decretação do Dia Nacional de Prevenção das Doenças Bucais com propostas de prevenção do câncer oral e aplicação de flúor, dentre outras;

- regionalização dos serviços e municipalização;

- aumento do subsídio para levar o dentista para a zona rural;

- fluoretação das águas e aplicação tópica de flúor;

- criação de departamentos de Odontologia autônomos, operacional e financeiramente, nas esferas federal, estadual e municipal;

- recursos humanos auxiliares;

- estabelecimento de um Conselho Nacional e Estadual de Odontologia com a participação de dirigentes de vários órgãos e mobilização nacional de direções odontológicas; $\mathrm{e}$

- promover a criação de fábricas de equipamentos simplificados nos estados. (ENATESPO, 1984)

É importante ressaltar a utilização de "política de saúde pública em Odontologia” e não de saúde bucal, o que expressa um espaço da saúde bucal coletiva ainda não consolidado. Ademais, no documento é feita a defesa do sistema incremental e da Odontologia simplificada, mas, também, de uma rede hierarquizada de serviços com maior autonomia dos municípios e estados assim como maior participação das universidades. O Enatespo surge em um cenário de abertura democrática e com um posicionamento de diálogo com o governo da Nova República frente aos problemas de saúde bucal da população brasileira, além de caracterização e crítica ao campo odontológico quanto à atuação do cirurgião-dentista. Segundo o Entrevistado 10 ademais constitui-se na convergência de interesses por participação no debate nacional sobre as políticas de saúde bucal até então monopolizado pela gestão do Inamps e das secretarias de saúde.

No informativo do Conselho Regional de Odontologia de São Paulo, de março de 1985, tratou-se das principais discussões realizadas no I Enatespo. O primeiro ponto retratado foi o apoio à bandeira da RSB com a garantia de acesso a serviços de assistência à saúde como direito básico de cidadania e dever do Estado brasileiro, além da transferência imediata do Inamps ao Ministério da Saúde. (CRO/SP, 1984) Participaram do evento muitos dentistas, dentre os quais cita-se o professor universitário Volnei Garrafa, da UnB, Hélio Wanderley Uchoa, que era da FSESP, Benedito Elias Waquim, do GT-Odonto, Vitor Gomes Pinto, do IPEA, Jovair Oliveira Arantes, filiado ao Partido do Movimento Democrático Brasileiro (PMDB), na época, e que depois se torna deputado federal, Sylvio Palermo Gevaerd, de Curiti- 
ba, e Paulo Capel Narvai, coordenador estadual de São Paulo. Djalmo Sanzi Souza também é citado como um dos organizadores do evento. (CRO/SP, 1984)

O II Enatespo ocorreu no ano seguinte, em 1985, na cidade de Curitiba (PR) e teve como tema central as Ações Integradas de Saúde (AIS). O evento defendeu a participação da Odontologia nas comissões técnicas das Comissões Interinstitucionais de Saúde (CIS) e nas Comissões Interinstitucionais Municipais de Saúde (CIMS), além de fazer um destaque para a necessidade do CFO incentivar a formação do pessoal auxiliar em Odontologia. (SERRA, 1998)

Já o III Enatespo ocorreu em Belém (PA), em setembro de 1986, tendo debatido a I Conferência Nacional de Saúde Bucal que ocorreria no mês seguinte, outubro de 1986. Os temas debatidos na terceira edição do evento foram:

- estrutura organizacional para atendimento escolar;

- participação efetiva da Odontologia nas AIS;

- sobretaxação de materiais odontológicos;

- classificação dos mesmos dentro do Ministério da Saúde e retirada do Imposto sobre Circulação de Mercadorias (ICMS);

- isonomia salarial e criação de cargos e cursos nas áreas de Técnico de Higiene Dental, Técnico em Prótese Dental e agentes de saúde.

As demandas por participação do dentista nas Comissões Interinstitucionais persistiam como alternativa para a participação efetiva da Odontologia nas AIS. (SERRA, 1998)

Os Enatespo estiveram relacionados com as políticas de saúde bucal, constituindo-se como polo dominante ou dominado, a depender do momento histórico, destinado à crítica das respostas do Estado aos problemas bucais da população. As discussões nos encontros culminavam em relatórios que apresentavam propostas para as políticas, com mudanças nos modelos de atenção apresentados ao longo dos anos, à medida que se lograva avanços no campo científico. Muitas pautas eram semelhantes àquelas do MBRO, a exemplo da recomendação de um Conselho Nacional e Estadual de Odontologia (1984) ou Conselho Nacional de Saúde Bucal (1988). Muitas propostas dos Enatespo foram contempladas na formulação das políticas de saúde bucal, como a fluoretação das águas, formação de pessoal auxiliar, sistema incremental voltado para o escolar, na política de 1989. Algumas destas propostas eram preconizadas desde a década de 1950, como o Sistema Incremental, pela FSESP, ratificadas pela Odontologia Sanitária e Social (Quadro 5). 
Observou-se poucas incorporações das propostas nas políticas do início da década de 1990. Em seguida, a proposta de inclusão da equipe de saúde bucal no PSF representava uma pauta dos Enatespo assim como as diretrizes da PNSB de 2004 expressam um conjunto de sugestões caracterizadas nos relatórios finais dos Encontros desde a década de 1980.

Alguns participantes e lideranças dos Enatespo exerceram funções de assessoramento da Coordenação de Saúde Bucal, ao longo dos anos, a exemplo de Sylvio Gevaerd, Djalmo Sanzi Souza, Paulo Capel Narvai, Marco Manfredini, Helenita Ely, Idiana Luvison, José Carrijo Brom, Rozangela Camapum, Moacir Tavares, Marcos Azeredo Werneck, Petrônio Martelli, Cleber Ronald Inácio dos Santos, Christian Mendez Alcântara, Marco Aurélio Peres. Destaca-se que todos os membros da Comissão de Assessoramento de 2004 eram integrantes dos Enatespo. Os funcionários da Divisão Nacional de Saúde Bucal assim como os gestores participavam dos Encontros, como Vitor Gomes Pinto, que esteve presente no primeiro Enatespo; Sonia Dantas e Gilberto Pucca Jr. também participaram dos eventos.

Os Enatespo ganharam proporções maiores incorporando ações do campo científico, como o Congresso Brasileiro de Saúde Bucal e apresentações de trabalhos científicos, assim como do campo burocrático, os Encontros dos Coordenadores Estaduais de Odontologia com o apoio do Ministério da Saúde.

\section{Quadro 5 - Principais críticas/propostas relacionadas às políticas de SB nos documentos dos Enatespo}

\begin{tabular}{|c|c|}
\hline Evento & Principais críticas/propostas relacionadas às políticas de SB* \\
\hline I Enatespo & $\begin{array}{l}\text { O relatório final expressou a elaboração de proposta de política de saúde pública em } \\
\text { Odontologia a nível nacional. Os participantes do evento recomendaram: incentivo } \\
\text { à Industria Nacional de Medicamentos para produção de insumos odontológicos; } \\
\text { padronizar as ações preventivas e curativas no nivel nacional, priorizando por faixas etárias } \\
\text { epidemiologicamente mais vulneráveis à cárie, utilizando a simplificação de acordo com } \\
\text { as necessidades locais; convênios com as universidades para encaminhamento de caso } \\
\text { que demandassem atenção especializada; decretação do Dia Nacional de Prevenção das } \\
\text { Doenças Bucais com propostas de campanhas de prevenção do câncer oral e aplicação } \\
\text { de flúor; aumento de subsídio para fixação do CD no meio rural; incentivo aos programas } \\
\text { preventivos - fluoretação das águas, bochechos com flúor, aplicação tópica de flúor, } \\
\text { comprimidos de flúor e aplicação de selantes; estabelecimento de um Conselho Nacional } \\
\text { e Estadual de Odontologia; implementação do sistema incremental, equipamento } \\
\text { simplificados, saúde do escolar; instituir cursos de formação de auxiliar de Odontologia e } \\
\text { Higienista Dental; definição de níveis de complexidades e responsabilidades crescentes em } \\
\text { relação ao atendimento odontológico - serviços básicos com o município, intermediário } \\
\text { com os governos estaduais e serviços especializados e complexos com o Ministério da Saúde } \\
\text { e Ministério da Previdência; desenvolver campanhas educativas de nível nacional. }\end{array}$ \\
\hline V Enatespo & $\begin{array}{l}\text { O relatório final apontou que os programas padronizados de âmbito nacional ou estadual } \\
\text { não podiam ser aceitos passivamente, a Divisão Nacional de Saúde Bucal (DNSB) deveria } \\
\text { providenciar para que fosse oficialmente criado o Conselho Nacional de Saúde Bucal (CNSB) } \\
\text { composto por representantes macrorregionais, estaduais e municipais. Esse Conselho } \\
\text { deveria ser responsável por formular o Programa Nacional de Saúde Bucal e deliberar } \\
\text { as medidas necessárias para a implantação. A DNSB deveria evitar pacotes técnicos } \\
\text { inadequados às realidades locais e apoiar as deliberações do I CNSB. Importância da } \\
\text { educação continuada e da formação do pessoal odontológico. }\end{array}$ \\
\hline
\end{tabular}




\begin{tabular}{|c|c|}
\hline Evento & Principais críticas/propostas relacionadas às políticas de SB* \\
\hline VI Enatespo & $\begin{array}{l}\text { O documento final reconheceu a criação da DNSB mas apontou para propostas ainda } \\
\text { não concretizadas: acesso universal, controle e avaliação, maior rigor nos produtos } \\
\text { odontológicos, remuneração justa e plano de carreiras para os trabalhadores, fluoretação } \\
\text { nas águas e no dentifrício, criação de um colegiado com representantes estaduais e } \\
\text { municipais. Críticas às lógicas de mercado hegemônicas. Quanto aos modelos assistenciais, } \\
\text { foram defendidos vários níveis de integração, sendo desenvolvida pela Administração direta. } \\
\text { O eixo condutor seria a redução dos níveis da cárie, periodontopatias e outras patologias. } \\
\text { Foi ratificada a importância do acesso a serviços de maior complexidade. As ações de saúde } \\
\text { bucal deveriam estar integradas num modelo de atenção integral à saúde das pessoas. } \\
\text { Foram também preconizados a formação profissional e a importância da intersetorialidade. }\end{array}$ \\
\hline VII Enatespo & $\begin{array}{l}\text { As ações de saúde bucal deveriam basear-se na Odontologia Integral, privilegiando a } \\
\text { manutenção e promoção da saúde bucal e buscando a redução e o controle das doenças } \\
\text { bucais no país. Os serviços deveriam ser reorganizados com base no novo modelo } \\
\text { assistencial com formação para as equipes de saúde bucal. Discutiu-se isonomia salarial e } \\
\text { definição de um plano de carreira adequado. A DNSB deveria consolidar-se como instância } \\
\text { política normativa e não executiva para formulação de diretrizes nacionais adequadas } \\
\text { às realidades locais. A PNSB deveria ser definida e implementada por um colegiado } \\
\text { com representantes de estados e municípios. A DNSB deveria posicionar a PNSB junto } \\
\text { às demais políticas de saúde, práticas sociais e econômicas do governo, consolidando a } \\
\text { municipalização. Deveria também incentivar a difusão das ações de educação para a saúde } \\
\text { bucal com trocas de experiências que sirvam de referências para os diversos serviços. }\end{array}$ \\
\hline VIII Enatespo & $\begin{array}{l}\text { Crítica às práticas odontológicas que não contribuíam para reversão do quadro } \\
\text { epidemiológico, necessidade de construção de novo modelo de atenção odontológica } \\
\text { baseado na universalidade, equidade, integralidade e controle social. Apontou-se a } \\
\text { necessidade de apoio politico-administrativo financeiro para a participação do componente } \\
\text { odontológico nos projetos municipais de saúde, busca pela implementação de modelos } \\
\text { assistenciais considerando a necessidade epidemiológica e sociais de cada região, } \\
\text { integralidade em saúde bucal. O projeto municipal de saúde precisava conter estudo } \\
\text { aproximado da realidade contemplando os determinantes sociais, a identificação de } \\
\text { problemas de saúde bucal a partir da epidemiologia, modelo assistencial baseado na } \\
\text { integralidade das açães de SB com ênfase nas açães básicas, método preventivo-educativo, } \\
\text { utilização de pessoal auxiliar, sistemas de trabalho de cobertura ampla, criar centros de } \\
\text { referência para atenção de níveis secundário e terciário, criar sistemas de referência e } \\
\text { contra referência, instrumentos adequados para avaliar o impacto das ações desenvolvidas, } \\
\text { definição clara dos recursos financeiros. Destacaram-se também os recursos humanos e } \\
\text { o controle social. Texto de autoria de Djalmo Sanzi Souza publicado na Revista do Cebes } \\
\text { dedicada ao Enatespo. Esse texto também foi entregue à coordenação de saúde bucal } \\
\text { no âmbito da consultoria prestada. O presidente do Enatespo foi Paulo Capel Narvai. } \\
\text { Comissão executiva: Djalmo Sanzi Souza, Joyce Capelli, Marco Aurélio de Anselmo Peres, } \\
\text { Paulo Fernando Capucci, Paulo Ivo Vantine, Rubens Mendes Diosdado, Tania Regina Feres } \\
\text { Siqueira. Comissão Científica: José Paulo Gouveia de Toledo e Marco Antonio Manfredini. } \\
\text { Paulo Frazão integrava a Comissão da Revista, juntamente com Carlos Botazzo. Douglas } \\
\text { Augusto Schneider Filho participou da Comissão de Comunicação Social. }\end{array}$ \\
\hline X Enatespo & $\begin{array}{l}\text { Discutiu a saúde bucal no processo de municipalização da saúde. Ocorreu debate sobre } \\
\text { "Políticas de saúde para a próxima administração federal” com representantes dos } \\
\text { candidatos à presidência da república. Foram apontados problemas de financiamento ao } \\
\text { SUS que se refletiam na saúde bucal. A assembleia deliberou por incentivar a participação } \\
\text { da sociedade no controle das ações de saúde bucal, posicionar a política de SB junto às } \\
\text { demais políticas de saúde, sociais e econômicas do governo no sentido de garantir sua } \\
\text { efetivação e repasse aos estados e municípios, consolidando a municipalização; estimular } \\
\text { políticas de educação em saúde bucal e de vigilância em saúde, negando a hegemonia do } \\
\text { modelo clínico predominante no Brasil; ampliar a fluoretação das águas; rejeitar critério de } \\
\text { financiamento baseado no pagamento por prestação de serviços e estabelecer parâmetros } \\
\text { e fluxos de repasse automático do nível federal para o municipal; colocar em prática que o } \\
\text { SUS deve ordenar a formação dos recursos humanos; estimular a formação de técnicos em } \\
\text { higiene dental (THD), auxiliar de consultório dentário (ACD), Técnico em Prótese Dentária } \\
\text { (TPD) e técnicos em manutenção de equipamentos, regulamentando a formação da equipe } \\
\text { em saúde bucal. Comissão relatora: Djalmo Sanzi Souza, Carlos Botazzo, Sergio Fernando } \\
\text { Torres de Freitas, Volnei Garrafa, Marco Aurélio de Anselmo Peres. Colaboradores: Paulo } \\
\text { Capel Narvai, Samuel Jorge Moyses, Sergio Benedito Franco. }\end{array}$ \\
\hline XII Enatespo & $\begin{array}{l}\text { O relatório final, intitulado Carta de Curitiba, recomendou a realização de inquérito } \\
\text { epidemiológico nacional, o estabelecimento de uma rede de informaçães epidemiológicas } \\
\text { sobre saúde bucal, mudança do modelo de atenção transcendendo seu caráter individual, } \\
\text { remuneração dos trabalhadores não pautada na produção. Lançamento da primeira edição } \\
\text { do Congresso Brasileiro de SBC, como atividade simultânea. Foi registrada neste Enatespo, a } \\
\text { inclusão da equipe de saúde bucal no PSF em Curitiba, em período anterior à formalização } \\
\text { federal feita no MS/CNSB. }\end{array}$ \\
\hline
\end{tabular}




\begin{tabular}{|c|c|}
\hline Evento & Principais críticas/propostas relacionadas às políticas de SB* \\
\hline XIII Enatespo & $\begin{array}{l}\text { Defendeu um modelo de atenção no qual a saúde bucal deixasse de ser privilégio das } \\
\text { elites para tornar-se "uma conquista da sociedade e obrigação do poder público"; o } \\
\text { aprofundamento das conquistas sociais e a presença do Estado como indutor das políticas } \\
\text { públicas. }\end{array}$ \\
\hline XIV Enatespo & $\begin{array}{l}\text { Inserção da saúde bucal no Piso de Atenção Básica (PAB), abordagem multidisciplinar para } \\
\text { atenção em saúde bucal, os programas de saúde bucal devem ser direcionados a partir da } \\
\text { epidemiologia e não selecionar determinados grupos populacionais para o atendimento, } \\
\text { incentivo à inclusão da SB no PSF, realização de outros inquéritos epidemiológicos que } \\
\text { contemplassem em seu desenho os determinantes sociais da saúde, consolidação da } \\
\text { equipe de saúde bucal (CD, THD, ACD, TPD, APD), promover capacitação integral dos } \\
\text { recursos humanos. O relatório registra uma moção de repúdio à coordenadora nacional de } \\
\text { saúde bucal, afirmando que ela não representava o posicionamento dos trabalhadores do } \\
\text { setor, afirmando que sua prática era contrária ao desenvolvimento e fortalecimento do SUS. }\end{array}$ \\
\hline XV Enatespo & $\begin{array}{l}\text { O relatório final apontou a precariedade das informações disponíveis sobre os montantes de } \\
\text { recursos destinados à saúde bucal, sendo que os dados disponíveis indicavam diminuição } \\
\text { dos recursos para área nos últimos anos; reconheceu a importância da inclusão dos } \\
\text { profissionais de odontologia (CD, THD e ACD) nas equipes de saúde da família e o Programa } \\
\text { de Agentes Comunitários de Saúde; reconheceu que o PACS e o PSF permitiam ir além das } \\
\text { estratégias restritas praticadas por privilegiar o território e a familia; reforçou a importância } \\
\text { dos procedimentos coletivos para a revisão dos quadros epidemiológicos e da superação } \\
\text { das dificuldades decorrentes dos diferentes padrões salariais entre os profissionais do } \\
\text { PSF, desenvolver mecanismos de educação continuada para profissionais do serviço não } \\
\text { inseridos no PSF, necessidade de fomento e ativação de centros formadores de pessoal } \\
\text { de nível médio; inclusão de dentistas na vigilância sanitária. Foram recomendados: } \\
\text { implementar incentivo no PAB aos municipios com ações de SB no PACS ou PSF, unicidade } \\
\text { e integralidade no papel do ACS frente ações preventivo-promocionais em saúde } \\
\text { bucal, reconhecer que o financiamento do setor era um desafio político "que requer do } \\
\text { coordenador de odontologia e equipe com maior capacitação técnica e ação estratégica } \\
\text { na captação dos recursos"; incorporar participação e saber popular nos serviços; realizar } \\
\text { estudos objetivos sobre o custo da Odontologia no Brasil; necessidade de integração entre } \\
\text { coordenadores estaduais e deste com a coordenação nacional; efetivar um apolítica salarial } \\
\text { para o SUS e implantação de cargos e salários. Relatoria: Paulo Capel Narvai, Djalmo Sanzi } \\
\text { Souza, Ruth Brito. }\end{array}$ \\
\hline XVI Enatespo & $\begin{array}{l}\text { Crítica à prática odontológica vigente. Necessidade de novas ações e medidas capazes de } \\
\text { regular práticas de mercado e/ou nos serviços públicos, assim como, de novos mecanismos } \\
\text { mais substantivos de relacionamento entre o Estado e mercado. Importância de construir } \\
\text { uma base política setorial nacional. Discutiu a Agenda } 21 \text { da saúde bucal e o acesso aos } \\
\text { serviços. Debateu o PSF e a saúde bucal em uma das oficinas temáticas com Flávio Andrade } \\
\text { Goulart, professor do departamento de Saúde Coletiva da UnB, um Sistema Nacional de } \\
\text { Informações em Saúde Bucal com o Paulo Capel Narvai, da Faculdade de Saúde Pública } \\
\text { (FSP) da USP. }\end{array}$ \\
\hline
\end{tabular}

*A partir da análise de relatórios finais, anúncios do evento, textos e programação divulgados, cedidos pelos entrevistados.

Fontes: elaboração pela autora. ${ }^{33}$

\section{Conferência Nacional de Saúde e I Conferência Nacional de Saúde Bucal}

A VIII Conferência Nacional de Saúde ocorreu entre 17 e 21 de março de 1986 e teve como temas "Saúde como Direito", "Reformulação do Sistema" e "Financiamento do Setor”. (BRASIL, 1986d; PAIM, 2008) Muitos participantes das três grandes mesas redondas eram vinculados ao movimento sanitário. Paim (2008)

33 A partir das revistas Ação Coletiva e dos documentos finais dos Enatespo. 
destaca, através da análise do relatório final da Conferência, que os principais elementos constitutivos do projeto da Reforma Sanitária foram construídos na VIII Conferência Nacional de Saúde:

- ampliação do conceito de saúde;

- reconhecimento da Saúde como um direito de todos e dever do Estado;

- criação do SUS;

- participação popular; e

- constituição e ampliação do orçamento social.

O relator geral da VIII Conferência foi Guilherme Rodrigues da Silva, tendo Solón Magalhães Vianna e Roberto Passos Nogueira como relatores.

A I CNSB ${ }^{34}$ incorporou as temáticas gerais da VIII CNS, tendo sido convocada pelo Ministério da Saúde, de 10 a 12 de outubro de 1986, em Brasília (DF), e contado com mais de 1000 participantes, entre representantes de entidades de classe, secretarias estaduais e municipais de saúde, Inamps, Associação Brasileira de Ensino Odontológico (Abeno), FSESP, Central Única dos Trabalhadores (CUT) e Comando Geral dos Trabalhadores (CGT), Associações de Moradores (Conam) e estudantes. Teve como temas:

- Saúde como direito de todos e dever do Estado;

- Diagnóstico de Saúde Bucal no Brasil;

- Reforma Sanitária: inserção da Odontologia no SUS; e

- Financiamento do setor de Saúde Bucal.

A I CNSB foi patrocinada pelo Ministério da Saúde e pela UnB. Esta Conferência representa parte do processo da Reforma Sanitária Brasileira que se constituiu em fórum para a aprovação de propostas específicas relativas à saúde bucal no Sistema de Saúde. No relatório final da Conferência, considerava-se que as conclusões produzidas representavam o que existia de mais democrático e progressista para a Odontologia e a sociedade civil organizada do país sobre saúde bucal até o momento. (BRASIL, 1986b) O estudo de Serra (1998) considerou que o evento representou o ápice de um processo longo e difícil de discussão da problemática de saúde bucal

34 A Conferência se estruturou em três dias: os dois primeiros foram iniciados com discussão em torno de grandes temas, no período da manhã; os grupos de discussões ficaram no período da tarde e a plenária final no último dia. 
da população brasileira de modo pluralista, essencialmente democrático, onde a população representada, teve voz e voto.

Volnei Garrafa, coordenador-geral; o presidente do CFO, Fernando de Souza Lapa; Paulo Freire, coordenador de Odontologia do Inamps; e Swendenberger Barbosa, secretário geral do evento formavam a comissão organizadora desta conferência. Na elaboração do relatório final estavam Carlos Botazzo, Lauro Nunes da Rosa, Ney Moraes, Renato Quintino dos Santos, com Jorge Cordón enquanto Assessor Especial. (BRASIL, 1986b) Paulo Frazão ${ }^{35}$ participou da Conferência como delegado e apontou que muitas teses aprovadas na conferência eram pautas do MBRO. ${ }^{36}$

Havia uma estreita articulação entre a CNSB e a VIII CNS. Lideranças do movimento sanitário, como Sérgio Arouca, Hesio Cordeiro e Cristovam Buarque, reitor da UnB, participaram da mesa "A saúde bucal: direito do cidadão e dever do Estado" ao lado de representantes das entidades odontológicas no período: Fernando de Souza Lapa, pelo CFO, Hésio Cordeiro, pelo Inamps, José Geraldo de Souza Jr., pela Conferência Nacional dos Bispos do Brasil (CNBB), Sergio Arouca, como presidente da $8^{\mathrm{a}} \mathrm{CNS}$ e Swendenberger Barbosa, como presidente do Sindicato dos Odontologistas do Distrito Federal (SODF).

No segundo dia, os painéis tratavam de "Reforma sanitária, a inserção da Odontologia no Sistema Único de Saúde" e "Financiamento do Setor" com os painelistas Eugênio Vilaça Mendes, pela Organização Panamericana da Saúde (OPAS)/OMS, Fabíola de Aguiar Nunes, representando o Ministério da Saúde, Paulo Capel Narvai, pelo Instituto de Saúde de São Paulo, Sério Pereira, pela Fundação de Educação do Governo do Distrito Federal, e Solón Magalhães Vianna, pelo IPEA. (BRASIL, 1986b)

No tema 1, destacou-se a posição da saúde bucal vinculada à luta pela melhoria de fatores condicionantes sociais, políticos e econômicos e se ressaltava a responsabilidade e o dever do Estado por sua manutenção. (BRASIL, 1986b) O relatório também apontou para a importância do controle social no planejamento, execução, monitoramento e avaliação dos Programas de Saúde Bucal.

No tema 2, a saúde bucal dos brasileiros foi adjetivada como caótica, apontando que apenas $5 \%$ da população tinham suas necessidades atendidas no modelo vigente, caracterizado como elitista, monopolizador, de altos custos de tecnologia densa, iatrogênico e mutilador. Somava-se a denúncia da inexistência de uma Política Nacional de Saúde Bucal voltada para os interesses da maioria da população assim como da ausência de recursos financeiros próprios ao setor e da falta de participação de controle da população nos programas. Foram também discutidos a inexistência

Entrevista concedida à autora, em São Paulo no ano de 2014. 
de dados epidemiológicos fidedignos, a pouca utilização de pessoal auxiliar, a não utilização de métodos preventivos de nível elementar coletivo, de forma sistematizada, o descumprimento da legislação quanto à fluoretação das águas, a ausência de ações de educação em saúde bucal, a "proliferação irracional de Faculdades de Odontologia” e a ausência de CD nos órgãos decisórios do atual sistema.

No tema 3, tratou-se que o "Programa Nacional de Saúde Bucal” deveria estar inserido no SUS. Foram abordadas a produção e a pesquisa em saúde bucal, a adoção de uma política de recursos humanos na saúde bucal, a formulação deste Programa como base nas diretrizes da área, respeitando as definições de cada esfera de gestão e estabelecendo as prioridades mínimas (faixa etária de 0 a 14 anos, gestantes, adulto, com concordância democrática da população atendida), a criação de prontuário único e o estímulo à organização comunitária e à ampla publicidade aos alimentos altamente cariogênicos, através de seus rótulos e propagandas. Discutiram o tema, Paulo Capel Narvai e Eugênio Vilaça Mendes com a coordenação de Swendenberger Barbosa. Mendes defendia o ponto de vista da articulação entre o Ministério da Previdência Social e o Ministério da Saúde, na perspectiva do que tinha sido o Prev-Saúde e as Ações Integradas de Saúde. Já Paulo Capel Narvai, entrevistado em 2014, defendia uma proposta de saúde bucal que ele identificava como de interesse do Movimento Operário Popular.

Essas posições podem se relacionar com a geração e as trajetórias. Eugênio Vilaça Mendes, nasceu em 24 de abril de 1940, em Pará de Minas (MG). Seu pai era dentista, sua mãe, professora primária e seus avós, comerciantes. Estudou em colégio privado, tendo optado pela Odontologia por influência de seu pai. Seguiu, primeiramente, a carreira de cirurgia, seguindo, posteriormente, pela Saúde Pública. Ele apresentava poucas disposições políticas, não tendo sido filiado a partidos políticos. Orientou sua carreira para a atuação em organismos internacionais tendo sido consultor da Odontologia Preventiva e Social (OPS), Banco Internacional para Reconstrução e Desenvolvimento (BIRD) e Fundação Kellog. Já Paulo Capel Narvai, nasceu em 15 de setembro de 1954, em Mandaguari (PR), filho de bancário, de mãe dona do lar e avós imigrantes agricultores. Optou pela Odontologia em virtude do seu caráter liberal e da autonomia profissional. Apresentava disposições políticas, tendo participado dos ECEO, era membro do Cebes de São Paulo e filiado ao Partido dos Trabalhadores (PT). Narvai apresentava maior capital político que Mendes, que, por sua vez, possuía maior capital científico que o primeiro, no período. Os dois apresentavam grande acumulação de capital burocrático.

Por fim, no tema 4, aprovou-se em plenário a criação de um Fundo Único Nacional de Saúde para o financiamento das ações, além da aplicação dos recursos 
nos níveis estadual e municipal. Cita-se, também, a isenção de impostos para a aquisição dos equipamentos odontológicos pelo setor público, a redução de impostos e taxas para importação de materiais odontológicos, além de uma demanda por dotação destinada e assegurada no Fundo Único de Saúde para a Saúde Bucal baseada nas necessidades populacionais.

Figura 3 - Capa do boletim do II ECEO

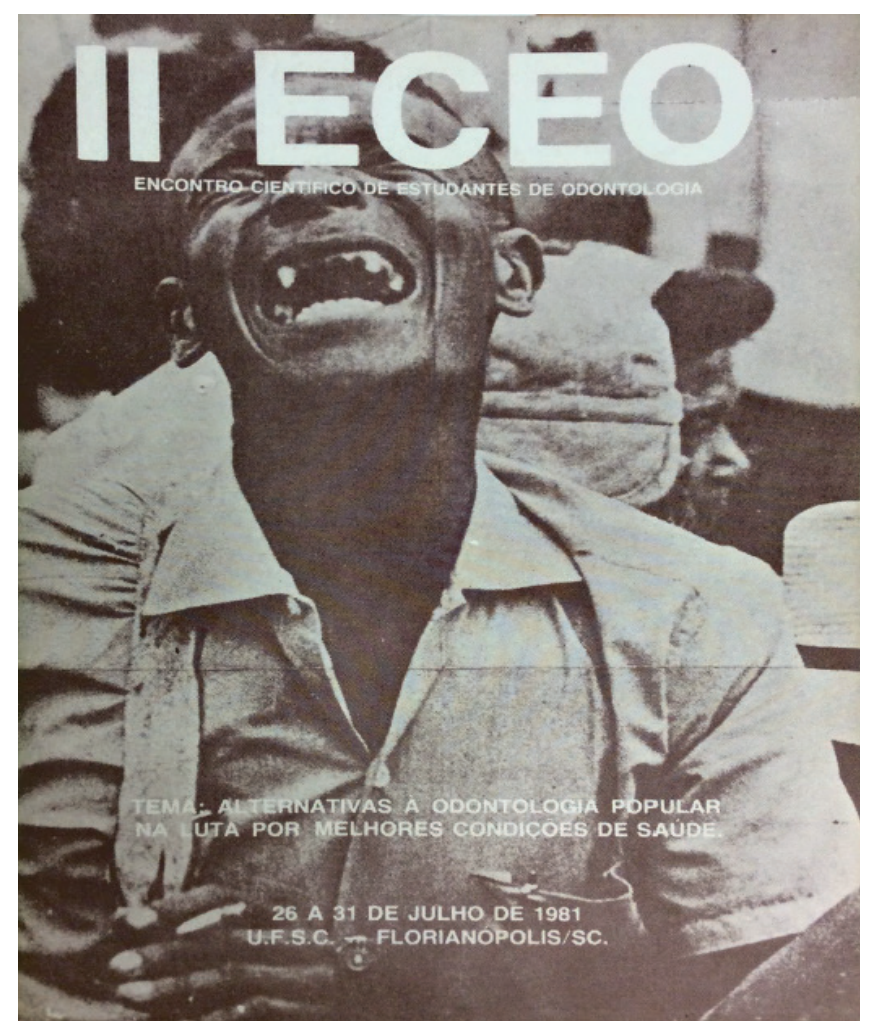

Nota: Charges que ilustraram os textos do II ECEO.

Fonte: Encontro Científico de Estudantes de Odontologia (1981).37

Antes de tratar especificamente do MBRO, cabe destacar que os ECEO juntamente com o Movimento e o Enatespo constituíram locais para discussão e crítica das políticas de saúde bucal. Eram espaços em favor da democratização da saúde, da universalização do acesso aos serviços de saúde bucal e do enfrentamento dos problemas odontológicos da população brasileira. Segundo o Entrevistado 15, muitos estudantes vinham tendo contato com o debate do fim da ditadura, da perspectiva de democratização e da possibilidade de uma outra Odontologia.

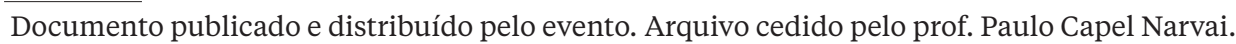


Os ECEO reuniam estudantes da área inspirados nos Encontros Científicos dos Estudantes de Medicina (ECEM), tendo sido organizados pelo movimento estudantil. Nesses encontros, eram debatidas questões relativas à democratização do país e sobre as políticas de saúde. O primeiro ECEO foi realizado no ano de 1979, na cidade de Vitória (ES), tendo sido precedido por discussões nos Pré-ECEO.

O II ECEO ocorreu em Florianópolis (SC), em 1981 (Figura 3). No boletim do II ECEO constaram textos sobre os temas:

- crítica à atual prática odontológica e suas relações com a formação de recursos humanos odontológicos, de Jorge Cordón;

- histórico da organização dos estudantes de Odontologia no Brasil;

- simplificação e desmonopolização em Odontologia, por Volnei Garrafa;

- considerações sobre a prática odontológica, por Paulo Capel Narvai;

- sobre a "História Social das Doenças", por Renato de Oliveira;

- a VII Conferência Nacional de Saúde. O Prev-Saúde em debate, publicado na revista Saúde em Debate pelo CEBES/Bahia.

\section{Movimento Brasileiro de Renovação Odontológica (MBRO)}

Muitos dentistas participaram dos ECEO: Volnei Garrafa, Jorge Cordón, Paulo Capel Narvai, Sérgio Pereira e Fernando Pires, como painelistas; e Marco Manfredini, Douglas Schneider, Marcos Werneck, Samuel Moysés e Paulo Frazão, como integrantes do movimento estudantil, dentre outros. O boletim era ilustrado com charges sobre diversos temas tratados no movimento sanitário, no MBRO e nos Enatespo, a exemplo da situação de saúde bucal dos brasileiros, da ditadura militar, da condição socioeconômica do país, dentre outros.

Ainda sobre as charges, destaca-se a ênfase no edentulismo, quando se observa um cidadão desdentado como símbolo da condição de saúde do cidadão brasileiro. A Pesquisa Nacional de Amostras por Domicílios (PNAD), do IBGE, publicada em 1986 mostrava que, dentre todos os brasileiros consultados que utilizaram serviços de saúde, apenas 4,8\% deles tiveram acesso a serviços odontológicos, com maior utilização dos residentes no Sul do país - Norte, 4,2\%; Nordeste, 4,4\%; Centro-Oeste, 4,6\%; Sudeste, 4,6\%; e Sul, 6,7\%. (IBGE, 1986)

Outros ECEO foram realizados, na década de 1980, e são considerados como responsáveis pela formação crítica dos profissionais da área de saúde bucal. (SERRA, 1998) De acordo com o Entrevistado 20, os ECEO levaram vários militantes para 
outros movimentos da época, como o MBRO e os Enatespo. Ademais, estudantes e profissionais que participaram dos ECEO passaram a integrar comissões de assessoramento no Ministério da Saúde, como Paulo Capel Narvai, Marco Manfredini e Marcos Werneck assim como Paulo Frazão, que integrou comissão sobre o inquérito epidemiológico nacional e também foi delegado na I CNSB.

Serra (1998), que analisou o MBRO, cita a iniciativa de dentistas do Conselho Regional de Odontologia de São Paulo (CRO-SP), da Associação Paulista de Cirurgiões Dentistas (APCD) e do Sindicato dos Odontologistas de São Paulo, em 1983, que criaram o Movimento de Renovação dos Odontologistas do Estado de São Paulo (MBROESP). O Entrevistado 20 apontou uma força aglutinadora do Movimento em São Paulo que impulsionou o MBRO no nível nacional.

[...] o Movimento de Renovação Odontológica do Estado de São Paulo foi o grande impulsionador do MBRO em nível nacional [...]. Por quê? Porque acho que em São Paulo houve um exemplo de uma unidade de forças contrárias ao então PDS que foi remanescente do ARENA do ponto de vista político-partidário. Então claramente eu entendo que na gênese, é lógico que não foi só São Paulo, mas eu acho que o exemplo político de construção de uma agenda coletiva aqui em São Paulo contribuiu muito para efetivação do Mbro em nível nacional. Você tem outros fatores que se somam também, você tem a questão dos ECEO que são os Encontros Científicos dos Estudantes de Odontologia, que foram retomados no final dos anos 70, que também acabaram por trazer vários militantes pra dentro do Mbro, você tem o surgimento dos Enatespos que são os Encontros Nacionais Administradores de Técnicos Serviços Públicos Odontológicos. [...] No nível nacional você tinha situações diferentes, sindicatos já identificados com propostas progressistas, serviços públicos onde você tinha técnicos trabalhando já identificados com gestões progressistas, intelectuais da universidade. [...]é um movimento que surge fruto daquela conjuntura política com vários agentes importantes na sua constituição. (Entrevistado 20, dentista)

Alguns meses após o I Enatespo foi fundado o MBRO. O Movimento, segundo seus boletins de divulgação, foi criado com o "intuito de estimular, a nível nacional a articulação dos profissionais da odontologia rumo a caminhos democráticos e populares”. (BOLETIM INFORMATIVO DO MOVIMENTO BRASILEIRO DE RENOVAÇÃO ODONTOLÓGICA, 1985a) O primeiro documento do MBRO, de fevereiro/ março de 1985, caracterizava o espaço de lutas e as distintas tomadas de posição dos dentistas: de um lado, aqueles dentistas e estudantes de Odontologia que tratavam a luta de resistência democrática ao lado dos profissionais e do povo e, do outro lado, as lideranças odontológicas que “davam os mais expressivos sustentáculos ao 
regime que condenava à miséria milhares de compatriotas e mergulhava o país na corrupção”. (BOLETIM INFORMATIVO DO MOVIMENTO BRASILEIRO DE RENOVAÇÃO ODONTOLÓGICA, 1985a) O boletim se opunha à mercantilização da prestação de serviços odontológicos e afirmava que o Estado brasileiro deveria assumir sua total responsabilidade e apoiava a expansão dos serviços próprios, a municipalização, o controle social, o aumento do financiamento para a assistência odontológica e a utilização de recursos humanos odontológicos. (BOLETIM INFORMATIVO DO MOVIMENTO BRASILEIRO DE RENOVAÇÃO ODONTOLÓGICA, 1985a)

Conforme o Entrevistado 20, muitos são os fundadores deste Movimento e, para organizar o processo inicial, foi criada uma comissão executiva provisória composta por João Roberto Peres Batista, de São Paulo, Paulo Capel Narvai, também de São Paulo e Volnei Garrafa, do Distrito Federal, que convocou assembleia do Movimento para 23 de março de 1985, em São Paulo.

Destaca-se que o MBRO se propunha a atuar em diversos âmbitos - sindicalismo, prática odontológica e formação de recursos humanos:

- contribuir para o estabelecimento de uma "Política Nacional de Saúde Oral” voltada para os interesses da maioria da população;

- luta pela liberdade política;

- oposição à mercantilização dos serviços odontológicos;

- democratização do acesso aos serviços de saúde bucal;

- apoio a movimentos populares;

- recursos humanos;

- ensino de qualidade;

- fortalecimento e democratização das entidades de classe odontológicas; e

- Luta na Assembleia Nacional Constituinte. (PRIMEIROS..., 1985)

O Movimento Brasileiro de Renovação Odontológica resulta do momento histórico de redemocratização do Brasil, das lutas pela saúde e no âmbito mais restrito da saúde bucal dentro da saúde, da grande insatisfação com os rumos da Odontologia pública, de como os programas eram definidos, das muitas críticas ao sistema incremental, ao modo de conduzir as definições dos programas da Odontologia pública, sobretudo no Inamps, mas, também, nas secretarias estaduais de saúde e educação, das características autoritárias, tecnocráticas, não abertas à gestão participativa, sem possibilidade de participação dos trabalhadores da área. Segundo o Entrevistado 10, as lutas dos profissionais de Odontologia apresentavam diver- 
gências, na década de 1980. Os entrevistados caracterizaram um ponto de vista das entidades de classe identificadas com a Odontologia liberal e de mercado com a defesa apenas dos interesses dos profissionais, mas, também, outro ponto de vista, do MBRO, de enfrentar o processo de assalariamento dos dentistas, etapa também vivenciada pela medicina, além da perspectiva de participar das lutas pela democracia e pela saúde no país. O MBRO aglutinava pessoas de distintos partidos políticos, mas com interesses semelhantes pelas pautas citadas.

A primeira coisa que eu acho era a saúde bucal pelos seus problemas e suas respostas versus a integração dela às outras áreas, acho que era o grande problema. Quando se discutia isso tudo em setores mais conservadores da Odontologia, que o importante era na base construir uma política de saúde bucal, onde a gente tivesse um aumento de recursos específicos para fazer [...] com que a estrutura da saúde bucal dentro de determinados órgãos do governo, seja federal, estadual, municipal, fosse reconhecida [...].Ou seja, de um lado um grau de corporativismo exacerbado, [...], numa visão muito elitista de que a gente ia se misturar [...]. (Entrevistado 23, dentista)

Sobre o movimento se chamar de renovação odontológica, os entrevistados apontaram razões distintas. O Entrevistado 3 remeteu a um espelhamento a posteriori do Movimento de Renovação Médica. O Entrevistado 15 também refere uma inspiração no movimento médico, mas aponta que não foi contemporâneo da Renovação Médica, tendo em vista que o MBRO já surgiu no processo de democratização. Já o Entrevistado 10 afirmou que o nome do Movimento remete aos seus objetivos de renovar as entidades odontológicas e as políticas de saúde bucal.

[...] chegou uma hora que tinha que dar um nome a isso, então era um movimento, movimento social, entendido como movimento social, então não tinha que ter diretoria, não tinha queterestatuto, não tinha que tersede, seria um movimentosocial que duraria enquanto ele fosse necessário como movimento social, que realizasse o seu objetivo. O seu objetivo era o que: renovar as entidades odontológicas e renovar as políticas de saúde bocal nas instituições pública. (Entrevistado 10, dentista)

No segundo boletim, intitulado "Primeiros Passos", destacavam-se os esforços maiores de participação e mudança de rota da Odontologia brasileira dos ECEO e dos Enatespo, assim como o inadiável surgimento do Mbro direcionado à contribuição para o estabelecimento de uma "Política Nacional de Saúde Oral" voltada para os interesses da maioria da população". (PRIMEIRO..., 1985, p. 1) Em São Paulo, decidiu-se que a assembleia geral seria o órgão máximo do Movimento 
e foi eleita a primeira coordenação nacional composta por Carlos Botazzo, Douglas Schneider, ambos de São Paulo, e Luiz Ben-Hur Loures, do Paraná. (PRIMEIRO..., 1985) Em entrevista concedida em 2014, Narvai estabelece alguns critérios para explicar que o MBRO concatenava pessoas de diversas vertentes:

- algumas pessoas da FSESP, chamados de primeiros sanitaristas;

- uma segunda geração de sanitaristas composta de pessoas como Sérgio Pereira;

- líderes dos movimentos estudantis;

- dentistas de organizações ligadas à luta clandestina contra a ditadura militar;

- pessoas que eram oriundas da academia; $\mathrm{e}$

- movimento sindical.

Além dos dentistas já citados, os entrevistados referiram outros dentistas que participaram do MBRO: Volnei Garrafa, Jorge Cordon, Lauro Consentino, Douglas Schneider, Marco Antônio Manfredini e Marcos Werneck.

Nos anos posteriores, ocorreram mudanças nas coordenações, como era pretendido pelo Movimento. De 1986 a 1987, fizeram parte da coordenação, Volnei Garrafa, Swendenberger Barbosa do Nascimento, Marcus Antônio Felix Ribeiro e Arlindo Gonçalves Ferreira. Os três primeiros eram de Brasília e o último de Belo Horizonte. No período seguinte (1987-1988) assumiram Luciano Elói Santos e Felix Araújo de Souza e Arlindo Gonçalves Ferreira permaneceu. Todos de Belo Horizonte. De janeiro a julho de 1989, integravam a coordenação nacional Douglas Augusto Schneider Filho, Paulo Capel Narvai e José Paulo Gouveia de Toledo (todos de São Paulo). (ZANETTI, 1993) O MBRO não possuía outra fonte de financiamento senão a de seus membros e neste sentido não realizava muitas reuniões nacionais. O MBRO não tencionava ser uma associação ou instituição, constituindo-se enquanto movimento que congregava dentistas de diferentes gerações e disposições políticas em torno de objetivos comuns. Muitos se conheciam antes desse período e, neste sentido, a articulação do grupo possibilitou a criação de um espaço de crítica e contestação das respostas do Estado frente aos problemas bucais.

No ano de 1985 houve intensa atividade do Movimento nos estados, com pauta sobre a assembleia constituinte, a retração do mercado de trabalho e o assalariamento dos dentistas, a formação de recursos humanos e pesquisa assim como crítica à prática odontológica então vigente. (O GRITO..., 1985) No boletim de agosto de 1985, trata-se sobre a população, que sempre esteve à margem de "uma atenção odontológica de boa 
qualidade”. (BOLETIM INFORMATIVO DO MOVIMENTO BRASILEIRO DE RENOVAÇÃO ODONTOLÓGICA, 1985b, p. 10) Caracterizava-se as entidades de classe como esvaziadas, bloqueando qualquer tipo de discussão e ausentando-se dos grandes debates nacionais. Além disso, afirmavam que enquanto os "dirigentes defendiam seus próprios interesses”. (BOLETIM INFORMATIVO DO MOVIMENTO BRASILEIRO DE RENOVAÇÃO ODONTOLÓGICA, 1985c, p. 12), a categoria enfrentava desemprego, salários e condições de trabalho péssimas nas empresas e clínicas populares, vínculos precarizados que "feriam a dignidade profissional". (BOLETIM INFORMATIVO DO MOVIMENTO BRASILEIRO DE RENOVAÇÃO ODONTOLÓGICA, 1985c, p. 12) Com isto, defendiam um novo sindicalismo, crítico e combativo. Destaca-se um predomínio de mensagens do "Centro-Sul” e uma crítica, no próprio boletim, que solicitava aos colegas dos outros estados que enviassem notícias. (BOLETIM INFORMATIVO DO MOVIMENTO BRASILEIRO DE RENOVAÇÃO ODONTOLÓGICA, 1985c) O Movimento se articulou ao projeto da Reforma Sanitária Brasileira.

O Movimento participou ativamente da primeira Conferência Nacional de Saúde Bucal, que foi um momento de grande expressão seu. Nos boletins que antecedem o evento, ficam nítidas as disputas entre o Movimento e as entidades de classe:

Os dentistas que integravam o MBRO tinham uma grande preocupação em registrar suas tomadas de posição através de boletins e, no ano de 1986, com o apoio do Cebes, os integrantes publicam seus textos em um número especial da revista Saúde em Debate, no número 18, de março/abril de 1986. A Revista tinha como temas Políticas de Saúde e Odontologia Comunitária e participação popular.

O MBRO participou do espaço da construção social das doenças bucais como um problema, posicionando-se criticamente frente aos problemas da população brasileira. Cada uma das tomadas de posição do MBRO será abordada quando tratarmos de cada uma dessas respostas do Estado, nos capítulos que se seguirão no presente trabalho. Nenhum dos dentistas entrevistados que fez parte do Movimento soube precisar quando ocorreu, especificamente, o seu fim. Entretanto, estudos de Serra (1998) apontam que a fase final do Movimento foi marcada por divergências internas quanto à fluoretação do sal no Brasil, no início da década de 1990, no governo Collor. Apesar de não existirem mais reuniões formais do Movimento, Entrevistado 15 acredita que as pautas do MBRO permanecem nas mentes e corações dos seus integrantes. Depois, participantes ocuparam cargos na política nacional, tendo fundado sindicatos nacionais como a Federação Interestadual dos Odontologistas (FIO), com Swendenberger Barbosa. De acordo com o Entrevistado 10 , outros integraram diretorias de sindicatos de odontologistas, disputaram e ganharam eleições para a $\mathrm{ABO}$ e suas regionais em vários pontos do país e começa- 
ram a exercer uma influência importante no próprio sistema do Conselho Federal de Odontologia (CFO) e Conselhos Regionais, a médio e longo prazo.

[...] as pessoas foram ocupando outros espaços, como muita gente era muito jovem também alguns foram tomando outros rumos profissionais, outra dimensão que foi o esvaziamento dos movimentos. Acho que nisso aí gente se pega o próprio processo da Reforma Sanitária já nos anos 90, a gente tem um refluxo dos movimentos e acho que há uma tendência das pessoas buscarem uma prática mais no seu local de trabalho, no seu âmbito, o que por um lado é positivo [...] e, por outro lado, o reflexo de um certo individualismo mesmo, a vida mais individual, menos espaços coletivos. (Entrevistado 15, dentista, professor universitário)

Considera-se que as principais bandeiras do MBRO, as mais imediatas, de certo modo, se resolveram com a conquista da democracia. Outras pautas também relacionadas ao movimento sanitário, como a saúde como um dever do Estado, a municipalização, o controle social, dentre outras, foram sendo contempladas com a implementação do Sistema Único de Saúde. Quanto às propostas específicas para as políticas de saúde bucal, o MBRO apontava diretrizes gerais a serem seguidas no nível nacional, mas não trazia muito detalhamento em suas propostas (Quadro 6). As políticas de saúde bucal incorporaram algumas pautas do Movimento. A PNSB de 1989 ratificou a fluoretação das águas, propostas de prevenção voltadas para a saúde do escolar, diretrizes voltadas à incorporação de pessoal auxiliar e reafirmou as práticas do Sistema Incremental. Pode-se afirmar que a incorporação da SB no Programa de Saúde da Família, que contou com fundadores do MBRO como consultores da Área Técnica de Saúde Bucal. A PNSB de 2004 também reforçou a fluoretação das águas, preconizou uma proposta mais abrangente de educação em saúde, recursos humanos, controle social, intersetorialidade, multiprofissionalismo e interdisciplinaridade, ampliação e qualificação da assistência.

Contudo, questões relacionadas à saúde bucal ainda estão na agenda, como o financiamento, o embate com os planos de saúde, com empresarial da saúde no campo odontológico, formação dos recursos humanos e crítica à prática odontológica vigente. Há, ademais, em concordância com Entrevistado 15, um desafio muito mais complexo, a tendência de isolamento da Odontologia com relação às outras profissões, a própria política nacional de 2004 que possui o mérito de ter produzido investimentos no setor, mas ainda expressa uma ação muito induzida pelo Ministério da Saúde. O entrevistado apontou que essas são questões que se precisa enfrentar e resolver para se consumar um sistema de saúde efetivamente transformador na saúde bucal. 


\section{Quadro 6 - Propostas e críticas específicas sobre as políticas de saúde bucal, nos documentos publicados pelo MBRO*}

\begin{tabular}{|c|c|c|}
\hline Boletim/ Revista & Propostas & Críticas \\
\hline $\begin{array}{l}\text { Boletim } n^{\circ} 1-\mathrm{fev} / \\
\text { mar - } 1985\end{array}$ & $\begin{array}{l}\text { Obrigatoriedade que o Estado assumisse a total } \\
\text { responsabilidade pela prestação de serviços } \\
\text { odontológicos, expansão dos serviços próprios, } \\
\text { municipalização, controle social, aumento } \\
\text { do financiamento com poderes para coibir a } \\
\text { mercantilização e poder para intervir no setor privado, } \\
\text { utilização de recursos humanos odontológicos } \\
\text { adequados à realidade socioeconômica e } \\
\text { epidemiológica, assim como sua justa remuneração. }\end{array}$ & $\begin{array}{l}\text { Prática odontológica } \\
\text { vigente, mercantilização } \\
\text { da prestação de serviços } \\
\text { odontológicos. }\end{array}$ \\
\hline $\begin{array}{l}\text { Boletim } n^{\circ} 2-\text { abril } \\
-1985\end{array}$ & $\begin{array}{l}\text { O boletim expressa o objetivo de "contribuir para o } \\
\text { estabelecimento de uma Política Nacional de Saúde } \\
\text { Oral realmente voltada aos interesses da maioria da } \\
\text { população" e ratifica as propostas do documento } \\
\text { anterior. }\end{array}$ & Idem boletim anterior. \\
\hline $\begin{array}{l}\text { Boletim } n^{\circ} 3-\text { maio } \\
\text { - } 1985\end{array}$ & O documento não expressa propostas. & $\begin{array}{l}\text { Os movimentos não } \\
\text { conseguiam influenciar } \\
\text { a implantação de } \\
\text { programas de saúde oral } \\
\text { que que privilegiassem } \\
\text { o atendimento "aos } \\
\text { enormes contingentes } \\
\text { populacionais, que vivem } \\
\text { à margem do sistema e } \\
\text { que, dispõem apenas de } \\
\text { serviços de baixíssima } \\
\text { qualidade para satisfação } \\
\text { de suas necessidades } \\
\text { historicamente } \\
\text { acumuladas". }\end{array}$ \\
\hline $\begin{array}{l}\text { Saúde em debate - } \\
\text { número especial do } \\
\text { MBRO - n 18/mar- } \\
\text { abr } 1986\end{array}$ & $\begin{array}{l}\text { Pressupostos: simplificação, desmonopolização } \\
\text { (principalmente incorporação progressiva de } \\
\text { pessoal auxiliar, ampliação do objeto de trabalho), } \\
\text { transferência dos conhecimentos, estimular } \\
\text { capacidade crítica, formação e capacitação de } \\
\text { diferentes recursos humanos, prevenção. Sugestões: } \\
\text { revisão do papel dos serviços privados, participação } \\
\text { popular, financiamento - definição de 10\% orçamento } \\
\text { da saúde para a Odontologia, concretização de um } \\
\text { "Plano Nacional de Saúde Bucal”, política de utilização } \\
\text { da mão-de-obra do dentista no sistema público que } \\
\text { estimule a sua interiorização, contratação em vínculo } \\
\text { direto em substituição aos contratos e convênios, } \\
\text { utilização do sistema incremental como forma de } \\
\text { massificar o tratamento odontológico, educação } \\
\text { para profissionais de outras áreas e para a população, } \\
\text { fluoretação das águas de abastecimento público, } \\
\text { inclusão de conteúdos de prevenção nos conteúdos } \\
\text { didáticos escolares em vários níveis de ensino, } \\
\text { estímulo à indústria nacional. }\end{array}$ & $\begin{array}{l}\text { À Odontologia Liberal, à } \\
\text { ganancia e manutenção } \\
\text { do status quo pelos } \\
\text { profissionais. Necessidade } \\
\text { de transformação da } \\
\text { odontologia restrita ao } \\
\text { dente para a estomatologia } \\
\text { que abrange todo o } \\
\text { sistema estomatognático, } \\
\text { conhecimento a ser levado } \\
\text { à prática concreta à maioria } \\
\text { da população. }\end{array}$ \\
\hline $\begin{array}{l}\text { Documento “As } \\
\text { prioridades do } \\
\text { MBRO" - setembro } \\
\text { - } 1987\end{array}$ & $\begin{array}{l}\text { Defesa das resoluções da } 1^{\circ} \text { Conferência Nacional de } \\
\text { Saúde Bucal. }\end{array}$ & $\begin{array}{l}\text { O documento não formula } \\
\text { críticas específicas às } \\
\text { políticas de saúde bucal. }\end{array}$ \\
\hline $\begin{array}{l}\text { Boletim MBRO, abril } \\
\text { - } 1990\end{array}$ & O documento não expressa propostas. & $\begin{array}{l}\text { Crítica ao modelo atual de } \\
\text { prática odontológica. }\end{array}$ \\
\hline
\end{tabular}

* Os outros boletins não trazem críticas ou sugestões explícitas às políticas de saúde bucal, tratando de temáticas já abordadas.

Fonte: elaborado pela autora. 


\section{Do GT - Odonto à Divisão Nacional de Saúde Bucal (DNSB)}

O grupo responsável por debater a Odontologia e os serviços básicos de saúde na VII Conferência Nacional de Saúde, em 1980, fez o registro do momento em que se discutiu, pela primeira vez, aspectos relacionados à Odontologia no Programa Nacional de Saúde. O grupo teve como facilitadores Sérgio Pereira, ${ }^{38}$ e João Audifax Cesar de Albuquerque, ${ }^{39}$ tendo sido relatada por Fernando Molinos Pires. ${ }^{40}$

O documento da VII CNS tratava do caráter ineficiente, descoordenado, mal distribuído, de baixa cobertura e alta complexidade, com enfoque curativo, caráter mercantilista e monopolista com inadequação no preparo dos recursos humanos. As alternativas eram voltadas para as ações básicas de saúde bucal; adequação da formação de recursos humanos de nível superior, mas também técnico e auxiliar; medidas impeditivas da utilização de equipamentos com alta densidade tecnológica nos serviços públicos; linha de pesquisa na produção de insumos básicos para a Odontologia, no intuito de minimizar a dependência externa; estímulo à formulação de convênios com secretarias estaduais, serviços municipais e universidades, em detrimento da compra de serviços do setor privado; criação, no Ministério da Saúde, de um núcleo técnico voltado aos "problemas da odontologia” que se responsabilize pelo planejamento das ações odontológicas no país e definição política até então inexistente. (CONFERÊNCIA NACIONAL DE SAÚDE, 1980)

Em 1982, o então ministro dr. Waldir Arcoverde ${ }^{41}$ e a gestão do Secretário Geral do Ministério da Saúde, Mozart de Abreu e Lima, que era cirurgião-dentista (VIANNA, 1988; ZANETTI, 1993) constituiu o Grupo de Trabalho de Odontologia, o GT-Odonto, através da Portaria $\mathrm{n}^{\circ} 191$, de 27 de julho de 1982. A sua finalidade era definir e orientar as ações do Ministério da Saúde no campo da Odontologia e integrar e coordenar as atividades de apoio às Secretarias Estaduais de Saúde. Três

38 Sérgio Pereira graduou-se em Odontologia em Lins, em 1958. Ingressou por concurso, em 1964, na Secretaria de Educação e Cultura do Distrito Federal. Foi um dos criadores do Programa Integrado de Saúde do Escolar (PISE), em setembro de 1977, e coordenou este programa por mais de uma década. (NARVAI, 1995)

39 João Audifax Cesar de Albuquerque graduou-se Odontologia, em 1948, no Distrito Federal (ESCOLAR, 1948), foi coordenador regional de saúde do sul Brasília (DF).

40 Fernando Molinos Pires concluiu a graduação (1964) e mestrado (1974) ambos na Universidade Federal do Rio Grande do Sul (UFRGS) e doutorado em Odontologia pela UFF em 1995. Foi presidente da Associação Brasileira de Saúde Bucal Coletiva (Abrasbuco) na década de 1990. Foi professor titular da UFRGS, de 1967 a 1995. Informações obtidas através do seu currículo lattes.

41 A gestão do ministro dr. Waldir Arcoverde apoiou a formação de grupos técnicos ligados a áreas específicas. (VIANNA, 1988) 
dentistas $^{42}$ foram designados para participar deste grupo de trabalho: Mércio de Azevedo Ferreira, Benedito Elias Waquim e Paula Piratininga, através da Portaria $\mathrm{n}^{\circ} 78$, de 8 de novembro de 1982, a qual também tratava das atribuições do grupo. Coube a Mércio de Azevedo Ferreira a gerência do GT-Odonto e apoiou esta iniciativa, José Alberto Hermógenes de Souza. O grupo ganhou destaque pelo financiamento do Finsocial.

Osdyr Brasileiro Matos, Solón Magalhães Viana e Vitor Gomes Pinto foram designados como assessores do GT, em caráter eventual. Ressalta-se, entretanto, um caráter de informalidade tendo em vista que esse GT não integrava o organograma do Ministério da Saúde. Vianna (1988), que analisou os relatórios do GT-Odonto, aponta que a atuação do grupo esteve mais relacionada a medidas de prevenção, através da fluoretação.

O GT atuou junto ao Instituto Nacional de Alimentação e Nutrição (INAN) e à FSESP, na operacionalização dos sistemas de fluoretação de águas de abastecimento público, que estavam paralisados em 30 localidades, e estenderam a implantação para novos sistemas de abastecimento público de água potável em 35 cidades. Em seguida, atuou no convênio BNDES/BNH/MS com alocação de recursos do Finsocial também na fluoretação das águas, promovendo proteção a quase metade da população brasileira (46\%). O GT-Odonto também atuou no inquérito epidemiológico, nas pesquisas sobre métodos alternativos de fluoretação e no apoio às ações desenvolvidas pelos estados. Os assessores do GT também participaram da formulação do Praod-Conasp, anteriormente tratado no presente estudo.

Em agosto de 1985, o GT-Odonto fez reivindicações sobre a criação da Divisão Nacional de Odontologia Social, com competências semelhantes àquelas elencadas na criação do GT, com quatro serviços: Serviço de Supervisão e Avaliação; Serviço de Programação e Normas Técnicas; Serviço de Epidemiologia; e Serviço de Desenvolvimento dos Recursos Humanos.

Ainda no início do ano de 1985, Vitor Gomes Pinto, no IPEA, Adriano Meireles, presidente do Conselho de Odontologia do Distrito Federal, e Ribamar Azevedo, da Associação Brasileira de Odontologia, conseguiram uma reunião com Tancredo Neves, novo presidente eleito. O encontro foi concedido graças à influência da secretária de Tancredo Neves, que era paciente do dr. Adriano Meireles. Eles elaboraram e entregaram uma proposta de Política de Saúde Bucal, juntamente com Ribamar Azevedo, presidente da ABO, e Swendenberguer Barbosa, presidente do Sindicato dos Odontologistas do Distrito Federal (SODF) e membro do MBRO. (GUERRA, 1985; PAULO, 1985b) O documento caracterizava as graves condições

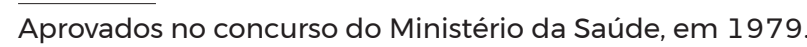


da população brasileira com relação às doenças bucais e sugeria a reestruturação da área odontológica no nível federal, a garantia do acesso a serviços odontológicos, no mínimo, para eliminação da dor e infecção, a formação de recursos auxiliares e sua utilização em práticas adequadas às necessidades da população e a adequação técnico-odontológica para tratamento precoce de grandes contingentes populacionais. No programa emergencial, propunham ampliar o programa de fluoretação das águas de abastecimento público. (FREIRE; BARBOSA, 1985)

No mesmo ano, Vitor Gomes Pinto, Sergio Francisco Piola e Solon Magalhães Vianna, no âmbito do IPEA, formulam um documento intitulado "A Política de saúde na nova república: subsídios para sua formulação”, a partir de estudo desenvolvido pelos mesmos no qual apontam estratégias importantes a serem desenvolvidas pelo Ministério da Saúde no novo governo.

Ainda em 1985, o Conselho Federal de Odontologia, através do seu presidente, reconhece e elogia o aumento do custeio da prestação de serviços odontológicos e afirma confiança devido ao financiamento da Odontologia da Previdência. Ao passo em que estes dentistas festejavam o aumento da verba da previdência (DENTISTAS... 1985), o Ministério da Saúde seguia com financiamento restrito para suas ações e os relatórios finais de eventos científicos apontavam a necessidade de ações de prevenção, conforme já mencionado. (SERAPHIM, 1985)

Entretanto, mesmo em meio ao movimento da Reforma Sanitária, a proposta da política de saúde bucal enfrentou muitas resistências no interior da Secretaria Nacional de Programas Especiais de Saúde (SNEPS)/MS, em 1986. (VIANNA, 1988)

Em 26 de agosto de 1987, é criada a Divisão Nacional de Saúde Bucal pela Portaria no 420, de 24 de agosto de 1987, publicada na seção I do Diário Oficial da União. A Divisão Nacional de Saúde Bucal integrou a Secretaria de Projetos Especiais do Ministério da Saúde.

Era quase que um costume da época. Você tinha os grandes programas no Ministério da Saúde de controle de doenças, malária, esquistossomose, febre amarela e tinha os grandes programas do Ministério. E também a estrutura do Ministério não era tão detalhada como é hoje. [...]dentro dos programas especiais tinha oftalmologia, tinha saúde do escolar e principalmente todos os programas que eram especiais na época. (Entrevistado 12, dentista, escritor)

A DNSB, composta por três serviços (Epidemiologia; Programação e Normas Técnicas; e Recursos Operacionais), passou a fazer parte do organograma do Ministério da Saúde, dentro da Secretaria de Projetos Especiais. As atribuições da DNSB pela portaria eram: 
fornecer subsídios para a definição da Política Nacional de Saúde Bucal; estabelecer diretrizes para o cumprimento desta política, através do programa nacional de saúde bucal, nas atividades de prevenção, manutenção e recuperação, de acordo com as atividades regionais do país; orientar, coordenar, normalizar e supervisionar as atividades da área; fomentar a participação comunitária no acompanhamento e avaliação das ações; incentivar o desenvolvimento de pesquisa e articular-se inter e intra-institucionalmente com órgão do Sistema Nacional de Saúde e do setor privado. (BRASIL, 1987b)

Os técnicos e gestores que estavam no Ministério da Saúde eram do grupo da Saúde Pública da USP e convidaram Vitor Gomes Pinto para ser o diretor da Divisão Nacional de Saúde Bucal. Dominou a DNSB do Ministério da Saúde, a vertente da Odontologia em Saúde Pública oriunda da Faculdade de Saúde Pública (FSP) da USP que se reproduziu nos estudos desenvolvidos e na política. Emergiu, nas entrevistas, a defesa de um grupo técnico que ocupou a gestão da DNSB, sendo contraposto pelo MBRO.

Mesmo tendo sido oficialmente publicado no Diário Oficial da União (DOU), em 6 de agosto de 1987, a reunião do MBRO, de 28 de junho de 1987, citou a criação da Divisão Nacional de Saúde Bucal como uma reivindicação histórica. Contudo, repudiou a forma de sua efetivação, pois colidiria com os princípios da I CNSB quanto aos aspectos ideológicos e organizacionais, tendo em vista que não contemplava a ampla participação dos profissionais e não assegurava o controle, por segmentos organizados da população, na formulação de uma Política Nacional de Saúde Bucal. (BOLETIM INFORMATIVO DO MOVIMENTO BRASILEIRO DE RENOVAÇÃO ODONTOLÓGICA, 1987)

O Boletim no 12 do MBRO, de1987, retrata divergências no seu interior pela súbita criação da DNSB, ao passo que o resumo da assembleia extraordinária aponta a desconsideração da existência de uma coordenação nacional no interior do movimento. Para Serra (1998), a criação do DNSB da maneira que se processou mostrou que o Movimento tinha um discurso para a sociedade "mais voltado para a democratização do que para as questões específicas da categoria”. O boletim do SODF, que tinha membros participando do MBRO, também manifestou seu repúdio à criação da DNSB nos moldes expostos. (ZANETTI, 1993)

A Portaria de criação da DNSB estabelece sua competência:

fornecer subsídios para a definição da Política Nacional de Saúde Bucal; estabelecer diretrizes para o cumprimento desta política, através do pro- 
grama nacional de saúde bucal, nas atividades de prevenção, manutenção e recuperação, de acordo com as atividades regionais do país; orientar, coordenar, normalizar e supervisionar as atividades da área; fomentar a participação comunitária no acompanhamento e avaliação das ações; incentivar o desenvolvimento de pesquisa e articular-se inter e intra-institucionalmente com órgão do Sistema Nacional de Saúde e do setor privado. (BRASIL, 1987b)

A primeira equipe de trabalho da DNSB foi composta por Vitor Gomes Pinto, o diretor; Mércio de Azevedo Ferreira, assessor e substituto do diretor; Benedito Elias Waquim, assessor; Maria Helena Porangaba, assessor; e os secretários Rosa Pimentel e Vaneide Martins. O grupo era misto, o diretor seguia os referenciais da FSP/USP e os assessores tinham formações distintas. Mércio Azevedo, oriundo de Pernambuco, tinha formação em saúde pública, já Benedito Waquim fez residência no Hospital do Câncer, ambos concursados do Ministério da Saúde. Acrescenta-se que outros profissionais trabalharam em outros períodos curtos, como Luiz Carlos Santos e os CD João Antônio Neto Caminha, Sylvio P. Gevaerd, Milton F. A. Silva e Arturo Delano de La Cruz. (ZANETTI, 1993) Em 1988, a DNSB trabalhou sem recurso próprio, dedicou-se: ao estudo da situação da odontologia brasileira, com a publicação do primeiro inquérito nacional em saúde bucal; às diretrizes operacionais da DNSB; à coordenação técnica; e ao apoio aos programas odontológicos dos estados e municípios. (SERRA, 1998; ZANETTI, 1993)

A partir dos resultados do inquérito epidemiológico realizado, a Divisão trabalhou no planejamento para a Política Nacional de Saúde Bucal e, em seguida, para a captação de recursos para o Programa Nacional para Controle da Cárie Dentária (Precad), segundo Pinto (1993) que afirma que o orçamento da União de 1989 continha a particularidade de uma dotação específica para ações de Saúde Bucal, aproximadamente $\mathrm{Cz} \$ 2,2$ milhões ( $\mathrm{R} \$ 15.611,14) .{ }^{43}$

Entretanto, a análise das Leis Orçamentárias Anuais (LOA) do Brasil na gestão de Sarney, de 1985 a 1989, mostra a existência de atividade específica da fluoretação de águas financiada pelo Plano Nacional de Saneamento (Planasa)/BHN, no Ministério do Interior, em 1985, e no Ministério do Desenvolvimento Urbano e Meio Ambiente, nos anos subsequentes. Apesar de existirem ações de saúde do escolar sendo desenvolvidas pelo MEC, estas atividades não constam no detalhamento da LOA. As ações odontológicas desempenhadas pela FSESP estavam em

43 Valor corrigido pelo índice IPCA-A para o ano de 2010, através da calculadora do cidadão do Banco Central do Brasil. 
uma rubrica mais ampla de assistência médica e sanitária ou assistência médica e odontológica, assim como não havia discriminação do orçamento para a saúde bucal no orçamento do MPAS. Neste sentido, o orçamento referente ao ano de 1989 expressa a primeira dotação específica para saúde bucal do Ministério da Saúde.

O orçamento para o exercício financeiro de 1985, continha baixíssima previsão de recursos para a saúde bucal, destinados à Fluoretação no Sistema de Abastecimento de Água (Planasa/BNH), pelo Ministério do Interior, além das ações no Ministério da Saúde, com atividades de assistência médica e sanitária, pela FSESP, que contemplavam a Odontologia. (BRASIL, 1984) Na LOA para o exercício de 1986, as atividades de fluoretação das águas pelo Planasa/BNH estavam a cargo do Ministério do Desenvolvimento Urbano e Meio Ambiente. Quanto à FSESP, uma entidade supervisionada do Ministério da Saúde no Orçamento Federal, constava assistência médica e odontológica e, também, o aumento dos recursos planejados, entretanto, não se individualizaram os gastos com a assistência odontológica ao interior da FSESP (Tabela 1). (BRASIL, 1985)

Na LOA para o ano de 1987, houve redução na previsão de recursos quando comparada ao ano anterior. A rubrica de assistência médica e sanitária continha a assistência médica e odontológica frente à meta de reduzir cárie dental em crianças de 6 a 14 anos. Na mesma rubrica, também estava prevista a redução da morbimortalidade da faixa produtiva da população. Quanto à fluoretação no sistema de abastecimento de água, este orçamento previa a meta de reduzir em $65 \%$ a prevalência da cárie dental da população de 7 a 14 anos de idade, através da fluoretação dos sistemas públicos de abastecimento de água prevista para 16 municípios e uma população beneficiada de 12.300 mil habitantes. (BRASIL, 1986a)

O objetivo da fluoretação permaneceu o mesmo no ano seguinte com aumento das metas: 75.000 ligações domiciliares, 12 sistemas de unidades de fluoretação de sistemas com 651 mil habitantes beneficiados, o que correspondia a menos de $1 \%$ da população brasileira naquele ano. A fluoretação das águas estava alocada no Ministério da Habitação, Urbanismo e Meio Ambiente. Já na FSESP, a meta para saúde bucal permaneceu a de "reduzir a incidência de cárie dental em crianças de 6 a 14 anos” com aumento no número de consultas planejadas. (BRASIL, 1987a) Já no orçamento para o ano de 1989, observou-se a especificação de atividade "Assistência à Saúde Bucal” com o objetivo de reduzir a prevalência dos problemas de saúde bucal. (BRASIL, 1989a) Houve subtração das outras rubricas.

Em 1985, o fina nciamento das ações da FSESP correspondia a 37,9\% do Ministério da Saúde, quando se somam os recursos para assistência com outras ações desenvolvidas por esta Fundação, além dos recursos destinados à sua gestão. 
Entretanto, o percentual total de custeio das ações da FSESP decresce ao longo do tempo, quando se analisa, comparativamente, o orçamento do Ministério da Saúde. No período analisado, ressalta-se a ausência de especificação da assistência odontológica da previdência nos orçamentos.

De 1985 a 1988, não foi possível verificar o percentual de recursos financeiros especificamente para a saúde bucal, na previsão do orçamento da União, tendo em vista que não existia o detalhamento para as ações da FSESP. No ano de 1989, foi possível verificar que se destinou $0,10 \%$ dos recursos do Ministério da Saúde, e $0,002 \%$ do orçamento da União, o que evidencia que as políticas de saúde bucal não eram priorizadas.

Tabela 1 - Distribuição dos recursos alocados para ações de saúde bucal, da função Saúde e Saneamento, do Ministério da Saúde e da União

\begin{tabular}{llllll}
\hline Ano & $\begin{array}{l}\text { Fluoretação das } \\
\text { águas }\end{array}$ & FSESP* & $\begin{array}{l}\text { Assistência } \\
\text { à SB }\end{array}$ & $\begin{array}{l}\text { Ministério da } \\
\text { Saúde }\end{array}$ & União \\
\hline & & & & & \\
1989 & $\mathrm{R} \$ 0,00^{*}$ & $\mathrm{R} \$ 0,00$ & $\mathrm{R} \$ 15.791 .289,80$ & $\mathrm{R} \$ 1.584 .354 .464,98$ & $\mathrm{R} \$ 750.424 .370 .543,54$ \\
& & & & & \\
1988 & $\mathrm{R} \$ 103.959 .186,42$ & $\mathrm{R} \$ 117.794 .298,42$ & $\mathrm{R} \$ 0,00$ & $\mathrm{R} \$ 5.807 .922 .635,91$ & $\mathrm{R} \$ 357.809 .776 .042,16$ \\
1987 & $\mathrm{R} \$ 9.875 .025,14$ & $\mathrm{R} \$ 59.687 .422,64$ & $\mathrm{R} \$ 0,00$ & $\mathrm{R} \$ 4.900 .696 .497,49$ & $\mathrm{R} \$ 210.233 .246 .564,61$ \\
1986 & $\mathrm{R} \$ 25.322 .573,84$ & $\mathrm{R} \$ 112.068 .515,79$ & $\mathrm{R} \$ 0,00$ & $\mathrm{R} \$ 7.658 .367 .367,02$ & $\mathrm{R} \$ 418.719 .798,77$ \\
1985 & $\mathrm{R} \$ 34.946 .008,83$ & $\mathrm{R} \$ 69.494 .699,00$ & $\mathrm{R} \$ 0,00$ & $\mathrm{R} \$ 3.699 .852,38$ & $\mathrm{R} \$ 194.107 .857,20$ \\
\hline
\end{tabular}

* Os valores destinados à FSESP para assistência médica e odontológica, sem os valores de gestão e outras rubricas.

Obs: Não havia especificação para as ações odontológicas na previdência na LOA desses anos.

Valores convertidos para real através da tabela de conversão do Banco Central do Brasil com correção do índice IPCA (IBGE) para fins de aproximação com o cenário atual.

De 1985 a 1988, não foi possível verificar o percentual de recursos financeiros especificamente para a saúde bucal na previsão do orçamento da União, tendo em vista que não existia o detalhamento para as ações da FSESP.

A partir dos valores na moeda Cruzado.

Fonte: adaptado de Brasil (1984, 1985, 1986a, 1987a, 1989a). 